\title{
$\omega$-3PUFA supplementation ameliorates adipose tissue inflammation and insulin-stimulated glucose disposal in subjects with obesity: a potential role for apolipoprotein $E$
}

\author{
James D. Hernandez ${ }^{1}$, Ting Li ${ }^{1}$, Eleanna De Filippis ${ }^{1, 凶}$ \\ ${ }^{1}$ Division of Endocrinology, Diabetes and Metabolism, Mayo Clinic Arizona, Scottsdale, AZ, USA
}

TO THE EDITOR:

We would like to thank the Editor for giving us the opportunity to respond to the comments made by Dr. Poledne R. et al. regarding our recent publication, “ $\omega-3$ PUFA supplementation ameliorates adipose tissue inflammation and insulin-stimulated glucose disposal in subjects with obesity: a potential role for apolipoprotein E" [1]. We also thank Dr. Poledne R. et al. for reading our work and appreciate their comment.

The authors have offered an alternative explanation for our findings. They suggest for our phenotype to be the result of changes in adipose tissue macrophage polarization. Although this would seem to be a reasonable interpretation of our data, we want to caution the authors on reaching such a conclusion. Indeed, we did not determine for the observed increase in APOE levels to be the principle mechanism responsible for the anti-inflammatory effect of fish oil supplementation. We proposed for APOE to play a role in this effect and postulated for a non-adipocyte source to decrease inflammation without an apparent change in macrophage number.

The work recently published by this group [2] was interesting, however, the study was conducted on subjects having a strikingly differing clinical profile than our study group. Their subjects have a normal BMI, include few lean diabetics (unknown whether type 1 or type 2 diabetes mellitus), and while the authors show evidence of tissue inflammation through the presence of resident proinflammatory macrophage, they provide no direct markers of localized inflammation. In addition, there is no determination of systemic inflammatory status nor evaluation of insulin resistance within their study group. Finally, we want to note that the study referenced was conducted on visceral fat, whereas our study was completed on subcutaneous fat, thus making a direct comparison difficult as these are distinctly different tissue types.

Reprints and permission information is available at http://www.nature.com/reprints

${ }^{\square}$ Correspondence and requests for materials should be addressed to E.D.F. defilippis.elena@mayo.edu. COMPETING INTERESTS

The authors declare no competing interests.

Publisher's note Springer Nature remains neutral with regard to jurisdictional claims in published maps and institutional affiliations. 
We strongly support the need for further studies which will help elucidate (1) the source of increased APOE we observed in our subjects, (2) the mechanism(s) responsible for the observed improvement in glucose disposal, and (3) the functional status of adipose tissue resident macrophage post-fish oil supplementation. APOE has been reported to have antiinflammatory properties [3-6]. M2 macrophage have been reported as a source of APOE $[7,8]$. As we did not detect a change in the overall numbers of macrophage, it is entirely reasonable to propose that the observed reduction of local tissue inflammatory markers is a function of a shift in polarity rather than number. However, since we did not perform flow cytometry to evaluate macrophage polarity in our samples, we cannot comment on this possibility.

We acknowledge that these observations require further exploration. However, based on the points noted above, we will continue to adhere to our original conclusions. Future studies can focus to determine the source of increased APOE levels, as well as utilize flow cytometry to assess macrophage polarity pre and post high dose fish oil supplementation.

\title{
Acknowledgments
}

\author{
FUNDING
}

EDF received support by Arizona Department of Health Services, Arizona Biomedical Research Commission (ABRC) (ADHS14-00003606), the Katryn H. and Roger Penske Career Development Award in Endocrinology in Honor of Dr Ian Hay, and Mayo Foundation, KL2 TR002379-02-01 CTSA.

\section{REFERENCES}

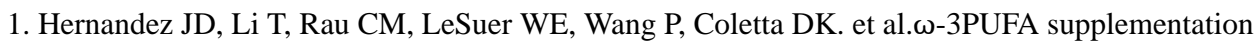
ameliorates adipose tissue inflammation and insulin-stimulated glucose disposal in subjects with obesity: a potential role for apolipoproteinE. Int J Obes (Lond). 2021;45:1331-1341. 10.1038/ s41366-021-00801-w.

2. Poledne R, Malinska H, Kubatova H, Fronek J, Thieme F, Kauerova S, et al.Polarization of Macrophages in Human Adipose Tissue is Related to the Fatty Acid Spectrum in Membrane Phospholipids. Nutrients. 2020;12:8.

3. Baitsch D, Bock HH, Engel T, Telgmann R, Müller-Tidow C, Varga G, et al.Apolipoprotein E induces antiinflammatory phenotype in macrophages. Arterioscler Thromb Vasc Biol. 2011;31:1160-8. [PubMed: 21350196]

4. Li K, Ching D, Luk FS, Raffai RL. Apolipoprotein E enhances microRNA-146a in monocytes and macrophages to suppress nuclear factor- $\kappa \mathrm{B}$-driven inflammation and atherosclerosis. Circ Res. 2015;117:e1-e11. [PubMed: 25904598]

5. Yue L, Bian JT, Grizelj I, Cavka A, Phillips SA, Makino A, et al.Apolipoprotein E enhances endothelial-NO production by modulating caveolin 1 interaction with endothelial NO synthase. Hypertension (Dallas, Tex: 1979)2012;60:1040-6.

6. Getz GS, Reardon CA. ApoE knockout and knockin mice: the history of their contribution to the understanding of atherogenesis. J Lipid Res. 2016;57:758-66. [PubMed: 27015743]

7. Mahley RW. Apolipoprotein E: cholesterol transport protein with expanding role in cell biology. Science (New York, NY). 1988;240:622-30.

8. Werb Z, Chin JR, Takemura R, Oropeza RL, Bainton DF, Stenberg P, et al.The cell and molecular biology of apolipoprotein E synthesis by macrophages. Ciba Found Symp. 1986;118:155-71. [PubMed: 3525037] 